\title{
Multicultural Marriages as Ethnic Bridges
}

\author{
Elli Heikkilä, Ph.D., Docent, Research Director \\ Institute of Migration, Turku, Finland
}

Heikkilä, Elli (ed.), Ritva Viertola-Cavallari, Päivi Oksi-Walter \& Jonna Roos (2004). Monikulttuuriset avioliitot sillanrakentajina [multicultural marriages as ethnic bridges]. Institute of Migration, Web Reports 2. 80 p. Available online at http://www.migrationinstitute.fi/db/articles/pdf/webreports2.pdf

The seminar "Multicultural marriages as ethnic bridges in Finland" has resulted in a report where multicultural marriages are studied from the viewpoint of research, juridical aspects and children's identity. The organization of the seminar was based on the final resolution on multi-cultural and new migrant families made by the Finnish Expatriate Parliament in 2002.

\section{Multicultural marriages in different countries}

According to Elli Heikkilä Finnish men in multicultural marriages usually had Russian or Estonian spouses in 2002. Spouses from Thailand and the former Soviet Union were next most common. During the time span 1991-2002 there were 4,854 marriages with Russian women, while marriages with Estonian women numbered 2,219. In 1,321 marriages the spouse came from Thailand and in 1,157 marriages from the former Soviet Union.

What about the choices Finnish women make? Most commonly the spouse was from Great Britain, USA, Sweden, Turkey, Russia and Germany in 2002. During the period 1991-2002 USA topped the list (1,438 marriages), Turkey was second $(1,306)$ and Great Britain was third $(1,033)$. Among these are tourist countries and countries where Finnish women work as au-pairs, study or are otherwise employed.

Ritva Viertola-Cavallari writes in her article that until the present members of the royalty and the nobility have usually searched for their brides within their own class in other countries. As a consequence all European royal families are more or less related to one another. Mixed marriages have also occurred among other groups who have been able to travel because of their profession and among those who have had international contacts, such as businessmen, artists, musicians etc. Modern 
transportation also enabled mass tourism, which has contributed to the increasing rate of mixed marriages all over the world. Globalization contributes to this trend and marriages between different races are common also outside the US. Many internet sites offer partners for mixed marriages.

According to Päivi Oksi-Walter the multicultural pair relationship provides many elements for a rich marriage. It is prone to problems, but the chances for a rewarding relation are better than average. Because of the different backgrounds there is much room for individuality and differences and thus a 'third culture' emerges in the family interaction. Many decisions are made on a more conscious basis, because no routine solutions are offered and decisions are not so easily made on unpredictable assumptions.

Greek-Finnish pairs have dated in spite of the distances between them, Johanna Järvinen-Tassopoulos concludes in the article based on her dissertation. Because of the geographical distance, contact after the first meeting was kept up by traveling between Finland and Greece. On the one hand, the intervals between the trips created a temporal distance, which could cause hesitation accentuating the spatial distance and the woman's alienation from the man. On the other hand, the time of separation also provided a possibility to think over the future of the relationship. The period of separation also fuelled romantic feelings and longing, which led to new trips. Also a distance created by waiting might emerge, and this was formed by the responsibilities and goals of both parties (studies, military service or work). Often the ethnic, cultural and linguistic distance was acknowledged in an early stage of the relationship.

Yrjö Männistö and Ella Lazareva conclude that marriage for love is comparatively rare between Finns and Russians, especially right from the beginning. Post-divorce marriage to a Finnish man may, however, be for love. Russian women have small chances of finding a suitable man to marry in their own country because of the widespread alcohol problem among men and the smaller number of men than women (partly as the result of war). Marriage for love would surely be the most preferred alternative for every Russian woman, but in reality such marriages are rare.

Most marriages are "artificial". The reason for this is generally that Russian women want to get away from poor living conditions in Russia and live a better life. Another reason might be that women want to move to another country for reasons of curiosity. Russia was closed to the rest of the world for such a long time that the desire to learn to know other countries is very strong. Especially young inexperienced women want changes. In a "trial marriage" the woman is happy if she succeeds, and if she does not, she divorces. Such marriages are insecure - often they deprive the woman of her wish to have a family. 


\section{Child abduction and child identity}

According to Outi Kemppainen, child abduction usually means a situation defined by the Hague convention on child abduction. Finland has abided by the Hague convention since August 1994. Between 10 and 15 applications are handled every year by the Ministry of Justice. These include applications sent abroad from Finland as well as applications coming from abroad to Finland. Only some of these have resulted in a court process for returning the children, because many cases have been resolved before any legal procedures have commenced. The applications have been withdrawn because the child has been voluntarily returned, or the parents have agreed on the custody of the child.

Minna Lähteenmäki asks in her article what it is like to live as a child in a family where both parents have different cultural and language backgrounds. Multicultural families often face the problem that the cultures of the persons closest to the children - the mother and father - pull them in different directions. When forming his/ her identity, the child must accept, reject or merge together norms and role models from two or more different cultures. It is not always easy to build an identity between the parents and their culture. The child may be proud of his/her identity when feeling solidarity with his/her family as well as with the surrounding culture and when continuously receiving a positive response from people around him or her. 
